\title{
Network meta-analysis of short-term effects of different strategies in the conservative treatment of AIS
}

Kepeng $\mathrm{Li}^{1}$, Jun $\mathrm{MiaO}^{2^{*}}$ and Jingan Zhang $^{2}$

\begin{abstract}
Purpose: To evaluate the short-term effects of different conservative treatments on in adolescent idiopathic scoliosis.

Methods: By searching the relevant literature of adolescent idiopathic scoliosis, the curative effects of the three regimens of bracing therapy combined with scoliosis-specific exercises, simple treatment with brace and simple scoliosisspecific exercises were compared. Review manager 5.3, Stata MP16 and Network software packages were used for Reticular Meta-analysis of Cobb's angles before and after treatment.

Results: A total of 364 patients were included in four clinical studies. Reticular meta-analysis showed that the shortterm effect of bracing treatment combined with scoliosis-specific exercises was better than that of treatment with brace and scoliosis-specific exercises, with effects of $2.71(95 \% \mathrm{Cl} 0.83-4.58)$ and $3.67(95 \% \mathrm{Cl} 1.21-6.14$ ), respectively. There was no statistical difference between simple bracing therapy and scoliosis-specific exercises.

Conclusion: Among the three common conservative treatments of adolescent idiopathic scoliosis, the short-term effect of bracing treatment combined with scoliosis-specific exercises is better than that of bracing treatment or scoliosis-specific exercises.
\end{abstract}

Keywords: Adolescent idiopathic scoliosis, Brace, Scoliosis-specific exercises

\section{Background}

Adolescent idiopathic scoliosis (AIS) is an unexplained three-dimensional malformation of the spine, with an incidence of about $2-3 \%$ in the population between 10 years of age and bone maturation [1]. AIS can lead to many problems such as limited function, pain, poor appearance and decreased quality of life [2, 3]. The most commonly used method for measuring the severity of scoliosis is the Cobb's angle, which is mainly used to measure the lateral angle of the spine on the frontal surface using standard anterior and posterior $\mathrm{X}$ radiographs [4]. Bracing therapy is a classic means for AIS's

\footnotetext{
*Correspondence: likepeng19801@163.com

${ }^{2}$ Tianjin Hospital, 406 Jiefang South Road, Hexi District, Tianjin, China

Full list of author information is available at the end of the article
}

conservative treatment to prevent scoliosis angle from increasing. Correct scoliosis by wearing braces so that scoliosis does not progress over time [5]. In addition to the living inconvenience and psychological pressure caused by the treatment of brace, there are also defects in the correction of three-dimensional malformation and aggravation of flat back deformity [6]. Therefore, people are trying to find a more proactive way to treat AIS.

Scoliosis-specific exercise (SSE) is commonly used to treat patients with mild to moderate scoliosis and consists of a set of scoliosis-specific exercise regimens, which is adjusted according to the patient's personalized scoliosis site [7], Cobb's angle, and clinical characteristics. SSE is mainly including three-dimensional active correction, daily life integration, stable correction posture, and patient education. SSE is divided into various schools, such as Schroth, SEAS, lateral shift, etc. The aim of SSE

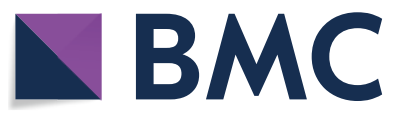

c) The Author(s) 2021. This article is licensed under a Creative Commons Attribution 4.0 International License, which permits use, sharing, adaptation, distribution and reproduction in any medium or format, as long as you give appropriate credit to the original author(s) and the source, provide a link to the Creative Commons licence, and indicate if changes were made. The images or other third party material in this article are included in the article's Creative Commons licence, unless indicated otherwise in a credit line to the material. If material is not included in the article's Creative Commons licence and your intended use is not permitted by statutory regulation or exceeds the permitted use, you will need to obtain permission directly from the copyright holder. To view a copy of this licence, visit http://creativeco mmons.org/licenses/by/4.0/. The Creative Commons Public Domain Dedication waiver (http://creativecommons.org/publicdomain/ zero/1.0/) applies to the data made available in this article, unless otherwise stated in a credit line to the data. 
is reducing the angle of scoliosis and preventing its progression and stabilizing the therapeutic effect [8].

So far, although both bracing therapy and SSE have become important means of conservative treatment of AIS, there is no systematic comparative study on the effects of different treatment options. A number of previous small sample studies have demonstrated better efficacy existing in treatment combining SSE with bracing, but the results remains controversial. To make clear the therapeutic effect of these three treatment schemes on AIS, the short-term curative effect of the treatment AIS is analyzed by net meta, which will provide a reference for the choice of treatment plan of mild to moderate AIS.

\section{Materials and methods}

\section{Search strategy}

The following computerised bibliographic databases were searched: PubMed, Ovid database, Cochrane library, Embase, and Google academic. Stepwise documentation of the entire search process was implemented. The publication time range of study was 1990-October 30, 2020. The conduction date of search was October 30, 2020.

The search queries was: AIS and (exercise therapy or PSSE or Schroth or SEAS or rehabilitation) and (orthosis or brace). Two authors were assigned to search database independently using the same strategy. Based on the inclusion and exclusion criteria, the authors independently reviewed the titles, abstracts and full-text articles retrieved in the initial search. Disagreements of the authors regarding accepting full-text articles were discussed until consensus was achieved.

\section{Study inclusion and exclusion criteria}

Inclusion criteria: (1) related study of AIS brace and SSE treatment; (2) inclusion of patient Cobb's angle $>10^{\circ}$; (3) prospective cohort design; (4) outcome variable included Cobb's angle.

Exclusion criteria: (1) the way of exercise is the study of popular sports, recreational activities and general physiotherapy. (2) Study was conducted in patients with non-specific scoliosis (congenital, neurological, post-traumatic). (3) Did not detail the options of SSE treatment.

\section{Data extraction}

The data were extracted and captured on a Microsoft Excel spreadsheet by one author to ensure continuity. Data extracted from the articles included the following categories:

method of random sequence generation, blind method in result measurement, description of missing data; patient inclusion criteria, follow-up time; data of the time, frequency, type, duration of SSE intervention; outcome measures. Three key criteria of randomization, allocation concealment and blindness in outcome measures published by the Cochrane team was used to evaluate Bias risk. The research team members cross-checked the information independently and the results of evaluation was compared to reach consensus.

\section{Data analysis}

The bias of the article was assessed using Revman5.3 software (Cochrane IMS). The effect variables used for merging were the mean of Cobb's angular difference (MD) and the standard deviation (SD) of difference before and after treatment. The Stata MP 16 and Network software package were used to analyze the Cobb's angle. First, the mesh diagram is made, and the inconsistency model is used to test consistency. If the $P$ value is greater than 0.05 , then the consistency model is used to analyze the data and make the forest map. The node splitting method is used to test the local inconsistency.

\section{Results}

Studies

According to the predetermined search strategy, 412 related documents were retrieved, including 407 in English and 5 in Chinese. The repeated literature, review, medical record report and experimental design literature were excluded by reading the title, leaving 55 articles. After reading the abstract and full text, the papers which not met the inclusion criteria were excluded in terms of the subjects and interventions. Finally four papers were included in study [9-12], including a total of 364 patients. The search strategy and results are illustrated in Fig. 1.

\section{Description of study sample}

Table 1 summarises the sample descriptions and interventions of the four included papers. All papers had small sample sizes, contributing to a total sample size of 364 participants, consisting of 56 in the bracing-SSE combined groups, 71 in the bracing groups and 39 in the SSE groups. All these SSE Schools have same aim and achieve them in the same order and time. The mean age of the participants among the studies ranged between 11.8 and 13.5 years. All the participants were diagnosed with AIS and were otherwise healthy. Bias evaluation of the four studies included are shown in Fig. 2.

\section{Results of net meta analyses}

The inconsistency model test was not significant $\left(\chi^{2}=\right.$ $0.68, P=0.41$ ), the consistency model can be used for data analysis. The forest plot showed that the Cobb's angle improvement in the brace-SSE combined groups is better than that of the other groups (Fig. 3). 


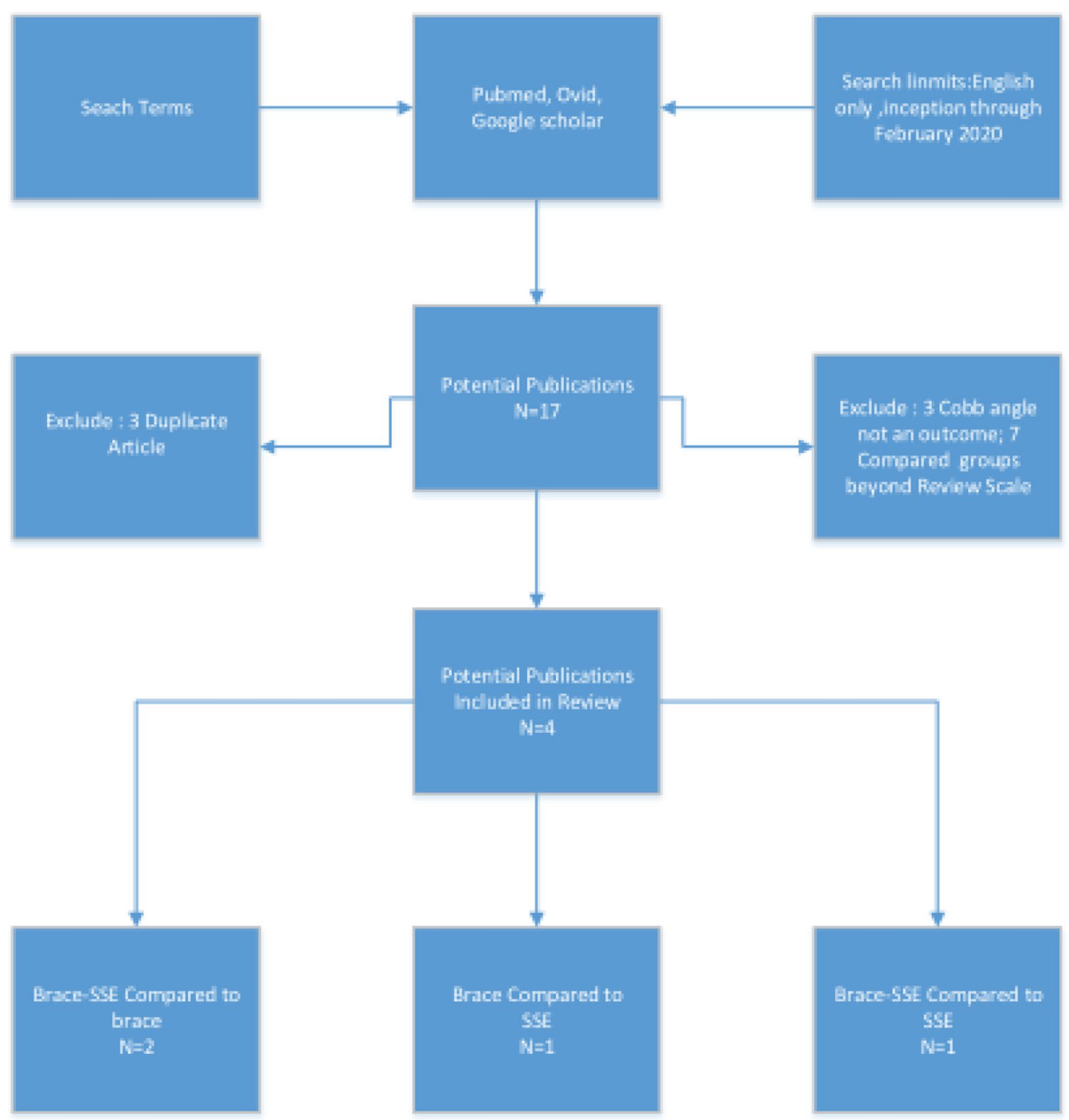

Fig. 1 Flow chart of the study

\section{Local inconsistency test}

There is no local inconsistency existed (Table 2).

\section{The comparative results}

The league table and comparative forest plot showed that the correction effect of bracing-SSE combined groups was better than that of simple bracing or SSE groups. Whereas there was no statistical difference between bracing and SSE groups. Table 3; Fig. 4 show the relative ranking results, whereas Table 4; Fig. 5 show the statistical differences among three groups.

\section{Discussion}

Brace and SSE therapy are both important means of AIS conservative treatment. The theoretical basis of bracing therapy is the application of external force to restore the spine in the malformed state to the physiological state, so that the spine can continue to grow in the physiological position, thus prevent the spinal deformity from progression [13]. Rehabilitation physicians should be part of the multidisciplinary team in AIS conservative treatment [14]. The main goal of the additional SSE exercise for bracing treatment is to eliminate or reduce the 
Table 1 Summary of the four included papers

\begin{tabular}{|c|c|c|c|c|c|c|c|}
\hline Study & Time (w) & $\mathrm{N}$ & $\operatorname{Sex}(f)$ & Age (y) & Inclusion criteria (Cobb's) & SSE & brace \\
\hline \multirow[t]{2}{*}{ Schreiber [10] (randomized control) } & 24 & & & & Age (10-18) & Schroth & \\
\hline & & & & & $\operatorname{Cob}\left(10^{\circ}-45^{\circ}\right)$ & $1 / d$ & \\
\hline 1 Brace-SSE & & 25 & 23 & 13.5 & & & \\
\hline 2 Brace & & 25 & 23 & 13.3 & & & \\
\hline \multirow[t]{2}{*}{ Zheng [1 1] (randomized control) } & 24 & & & & Age (10-17) & SEAS & TLSO \\
\hline & & & & & $\operatorname{Cob}\left(10^{\circ}-40^{\circ}\right)$ & $1 / d$ & \\
\hline 3 SSE & & 29 & 22 & 12.4 & & & \\
\hline 2 Brace & & 24 & 19 & 12.3 & & & \\
\hline \multirow[t]{2}{*}{ Gao [9] (randomized control) } & 24 & & & & Age (10-1 year postmenstruation) & SEAS & TLSO \\
\hline & & & & & $\operatorname{Cob}\left(25^{\circ}-40^{\circ}\right)$ & $1 / d$ & \\
\hline 1 Brace-SS & & 23 & 18 & 12.2 & & & \\
\hline 2 Brace & & 22 & 18 & 12.1 & & & \\
\hline \multirow[t]{2}{*}{ Sayyad [12] (cohort) } & 12 & & & & Age (6-16) & $1 / d$ & Milwaukee \\
\hline & & & & & $\operatorname{Cob}\left(15^{\circ}-45^{\circ}\right)$ & & \\
\hline 1 Brace-SSE & & 8 & 4 & 12.1 & & & \\
\hline 3 SSE & & 10 & 6 & 11.8 & & & \\
\hline
\end{tabular}

Random sequence generation (selection bias)

Allocation concealment (selection bias)

Blinding of participants and personnel (performance bias)

Blinding of outcome assessment (detection bias)

Incomplete outcome data (attrition bias)

Selective reporting (reporting bias)

Other bias
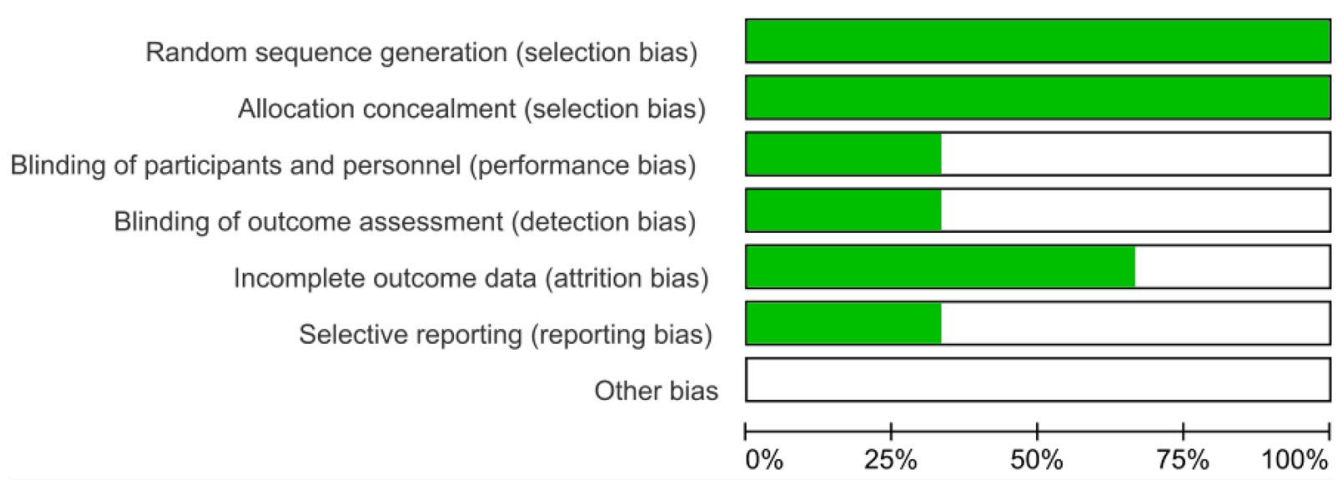

Low risk of bias

Unclear risk of bias

High risk of bias

Fig. 2 Risk of bias for included studies

side effects (flat back deformity, disuse muscle atrophy) caused by bracing treatment. In fact, the sponsors of SSE are not intended to replace brace treatment, but to be used in combination with brace as an auxiliary intervention, though SSE alone may temporarily reduce the Cobb's angle of AIS [15].

For the outcomes, the net meta-analyses showed that brace-SSE results in greater improvement of spinal deformity at follow-up (Cobb angle) in comparison with pure brace or SSE interventions. The time-dependent passive mechanism of bracing therapy combined with active correction mechanism can bring more benefits to patients. Previous controlled studies on the curative effect between brace and SSE showed that the outcomes of brace treatment was better than that of SSE $[16,17]$.
Schreiber et al. [18] observed that adding SSE might address a need and offer a treatment complement in patients who are not fully compliant with brace treatment. Consistently with previous studies, our outcomes suggested that adding SSE to bracing would lead to better outcomes, as compared to bracing alone. However, there was no statistical difference found between brace and SSE in this net meta. The difference of results may exist in the short follow-up time of included study. Due to the time-dependent passive correction mechanisms, the advantages of brace will not be spotted in a short 24-week period.

SSE consist of a program of curve-specific exercise protocols which are individually adapted to a patients' curve site, magnitude and clinical characteristics [19]. There 


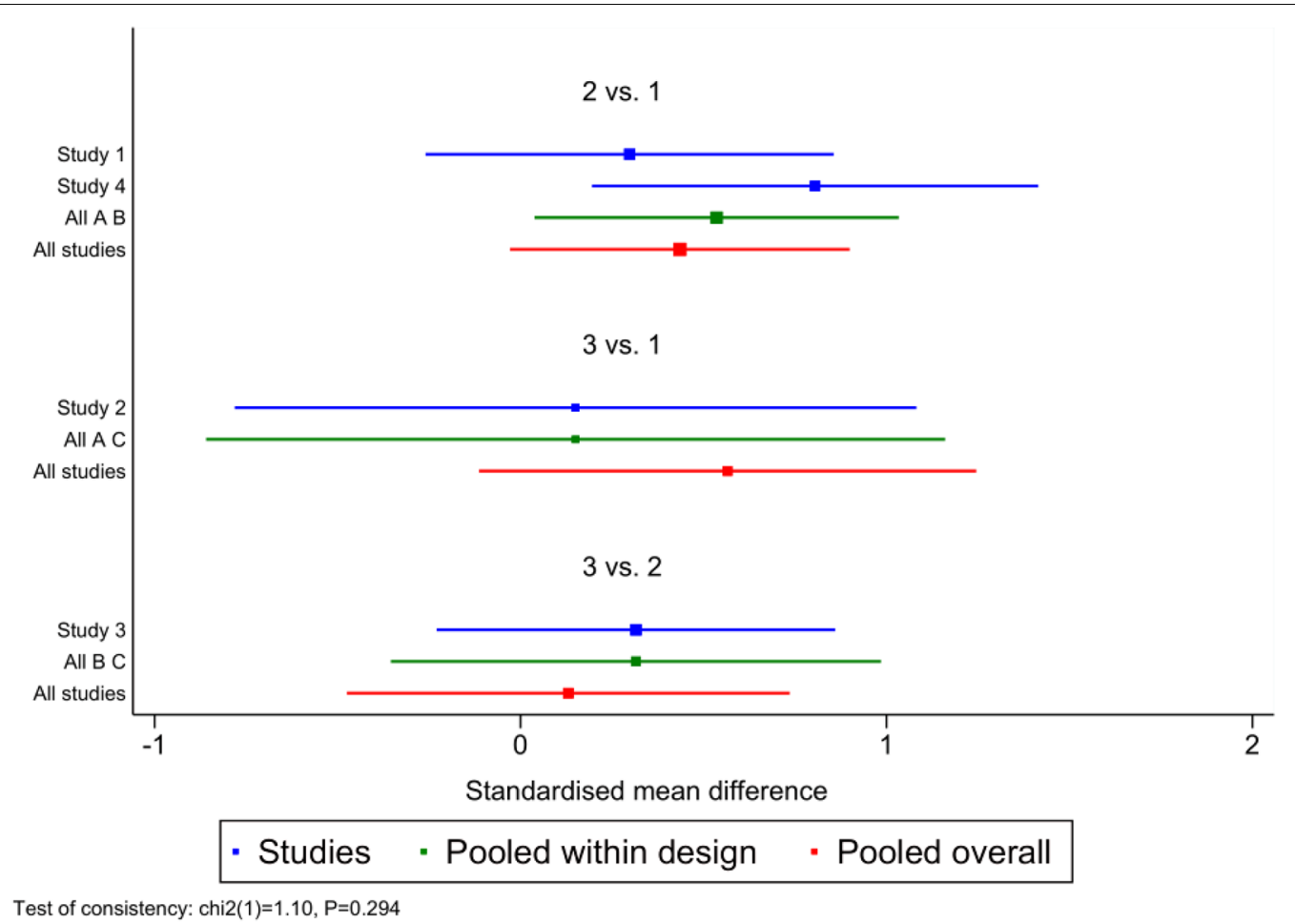

Fig. 3 Forest plot of the three groups. 1 A: Bracing-SSE combined groups; 2 B: bracing groups; 3 C: SSE groups

Table 2 Results of local inconsistency tests

\begin{tabular}{|c|c|c|c|c|c|c|c|}
\hline \multirow[t]{2}{*}{ Side } & \multicolumn{2}{|l|}{ Direct } & \multicolumn{2}{|l|}{ Indirect } & \multicolumn{3}{|c|}{ Difference } \\
\hline & Coef. & Std. Err. & Coef. & Std. Err. & Coef. & Std. Err. & $P>|z|$ \\
\hline$A B$ & 2.932 & 0.995 & -0.040 & 3.476 & 2.972 & 3.616 & 0.411 \\
\hline$A C$ & 1.120 & 3.351 & 4.092 & 1.357 & -2.972 & 3.616 & 0.411 \\
\hline$B C$ & 1.160 & 0.922 & -1.812 & 3.496 & 2.972 & 3.616 & 0.411 \\
\hline
\end{tabular}

Table 3 Treatment Relative Ranking

\begin{tabular}{lccl}
\hline Treatment & SUCRA & PrBest & Mean rank \\
\hline Brace-SSE & 99.8 & 99.6 & 1.0 \\
Brace & 43.0 & 0.2 & 2.1 \\
SSE & 7.2 & 0.1 & 2.9 \\
\hline
\end{tabular}

are several schools under the SSE banner focused on the treatment of AIS, each of the schools promotes a unique technique and unique exercises. However, the methods' overall goals are the same, as each method seeks to treat all the 3D scoliosis deformity by realigning the spine, rib cage, shoulders and pelvis to 'normal' anatomical postures [20]. Many professionals of AIS are usually not clear the different value between bracing treatment and SSE: while some experts overestimate the importance of SSE, The other part underestimates its importance. The evidence about the effectiveness of SSE is growing, with more high quality research studies being published in recent years. As the results of our net meta research displayed, AIS patients can take maximum benefits only when the brace-SSE treatment take place. The results are consistent with previous studies.

\section{Limitations}

Although only four papers were included in this mesh meta, the included population and intervention characteristics of the literature were similar, comparable and transferable. With the prolongation of interventional 


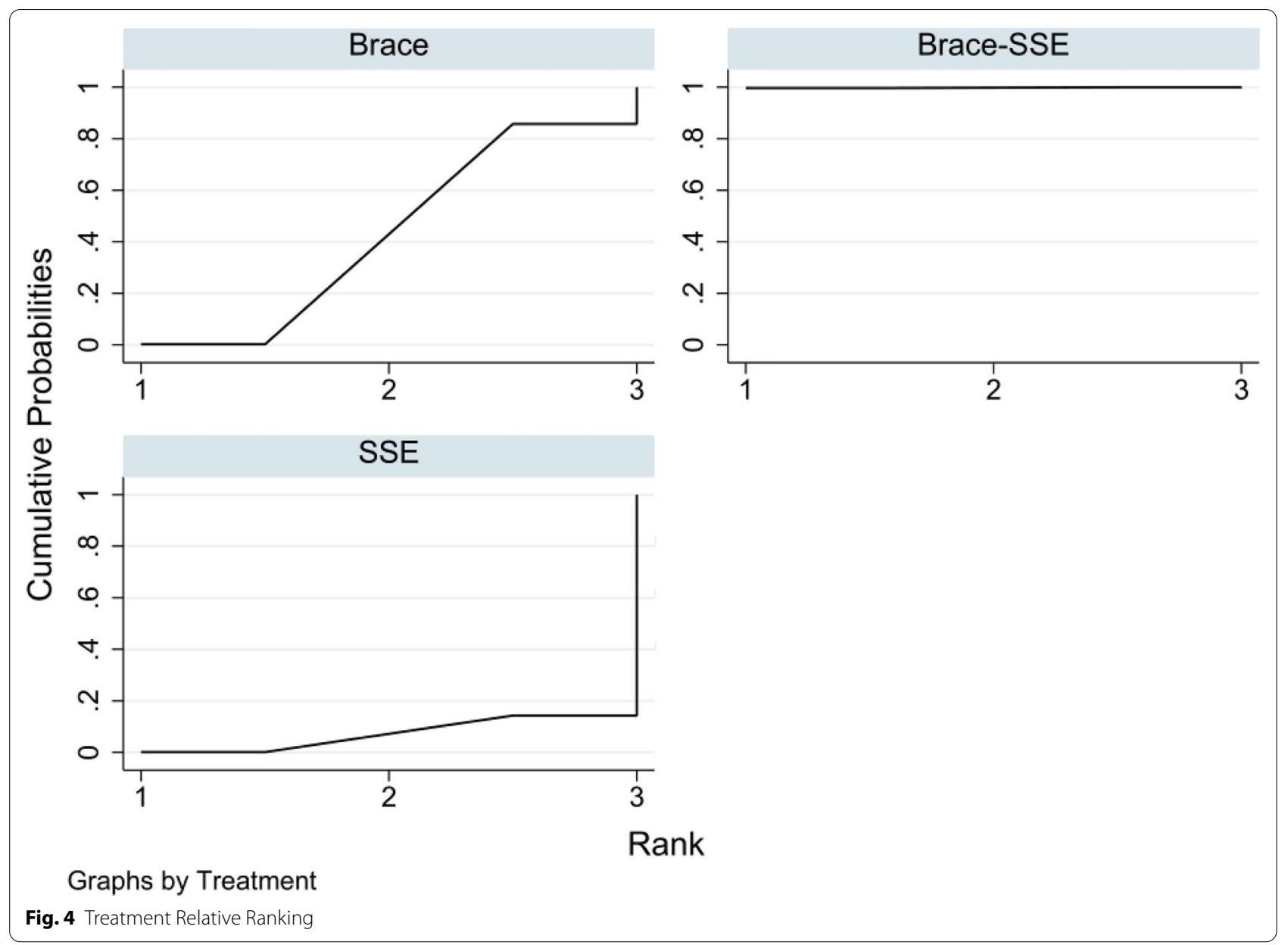

Table 4 League table

\begin{tabular}{lll}
\hline Brace-SSE & Brace & SSE \\
\hline Brace-SSE & $2.71(0.83,4.58)$ & $3.67(1.21,6.14)$ \\
$-2.71(-4.58,-0.83)$ & Brace & $0.97(-0.78,2.72)$ \\
$-3.67(-6.14,-1.21)$ & $-0.97(-2.72,0.78)$ & SSE \\
\hline
\end{tabular}

time, the interference of compliance factors on the results increased. The study reasonably controlled the influence of confounding factors on the outcome judgment by including papers in which the interventional time are about 24 weeks.

\section{Conclusion}

For conservative treatment of AIS, the combination of bracing and SSE treatment is significantly better than single brace or SSE treatment. Clinical AIS treatment should include the team collaboration of rehabilitation physicians, clinicians.

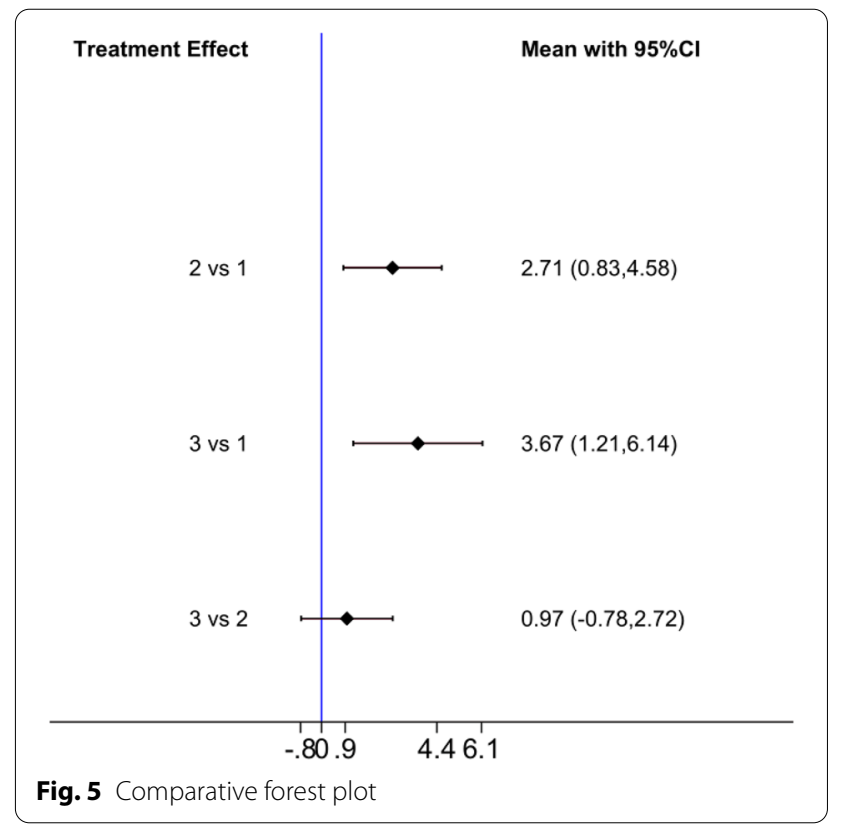




\section{Acknowledgements \\ Not applicable.}

\section{Authors' contributions}

JM conceived and designed the study. JAZ analyzed the data. KPL wrote the manuscript. All authors read and approved the final manuscript.

\section{Funding}

Not applicable.

\section{Availability of data and materials}

Data available within the article or its supplementary materials.

\section{Declarations}

\section{Ethics approval and consent to participate}

Not applicable.

\section{Consent for publication}

Written informed consent for publication was obtained from all participants.

\section{Competing interests}

The authors declare that they have no competing interests.

\section{Author details}

${ }^{1}$ Second Central Hospital of Baoding, 57 Fan Yang Middle Road, Zhuozhou, Baoding, Hebei, China. ${ }^{2}$ Tianjin Hospital, 406 Jiefang South Road, Hexi District, Tianjin, China.

Received: 25 November 2020 Accepted: 7 June 2021

Published online: 13 June 2021

\section{References}

1. Menger RP, Sin AH. Adolescent and idiopathic scoliosis. Treasure Island: StatPearls Publishing; 2020.

2. Hawary RE, Zaaroor-Regev D, Floman Y, Betz RR, et al. Brace treatment in adolescent idiopathic scoliosis: risk factors for failure-a literature review. Spine J. 2019;19(12):1917-25.

3. Roye BD, Simhon ME, Matsumoto H, et al. Establishing consensus on the best practice guidelines for the use of bracing in adolescent idiopathic scoliosis. Spine Deform. 2020. https://doi.org/10.1007/ s43390-020-00060-1.

4. Trac S, Zheng R, Hill DL, Lou E. Intra- and interrater reliability of Cobb angle measurements on the plane of maximum curvature using ultrasound imaging method. Spine Deform. 2019;7(1):18-26.

5. Dolan LA, Weinstein SL, Abel MF, et al. Bracing in adolescent idiopathic scoliosis trial (BrAIST): development and validation of a prognostic model in untreated adolescent idiopathic scoliosis using the simplified skeletal maturity system. Spine Deform. 2019;7(6):890-8.

6. Weniger CD, Fujak A, Hofner B, Fuchs M, Forst R, Richter RH. Long-term results of conservative therapy of adolescent idiopathic scoliosis using the Cheneau brace. Langzeitergebnisse nach konservativer therapie der idiopathischen adoleszenten skoliose mit Cheneau-korsett. Klin Padiatr. 2019;231(5):248-54.

7. Day JM, Fletcher J, Coghlan M, et al. Review of scoliosis-specific exercise methods used to correct adolescent idiopathic scoliosis. Arch Physiother. 2019;9:8.

8. Kuru T, Yeldan I, Dereli EE, et al. The efficacy of three-dimensional Schroth exercises in adolescent idiopathic scoliosis: a randomized controlled clinical trial. Clim Rehabil. 2016;30(2):181-90.

9. Gao C, Zheng Y, Fan C, et al. Could the clinical effectiveness be improved under the integration of orthotic intervention and scoliosis-specific exercise in managing adolescent idiopathic scoliosis?: a randomized controlled trial study. Am J Phys Med Rehabil. 2019;98(8):642-8.

10. Schreiber S, Parent EC, Khodayari Moez E, et al. Schroth physiotherapeutic scoliosis-specific exercises added to the standard of care lead to better cobb angle outcomes in adolescents with idiopathic scoliosis - an assessor and statistician blinded randomized controlled trial. PLOS ONE. 2016;1 (12):e0168746.

11. Zheng $Y$, Dang $Y$, Yang $Y$, et al. Whether orthotic management and exercise are equally effective to the patients with adolescent idiopathic scoliosis in mainland China?: a randomized controlled trial study. Spine. 2018:43(9):E494-503.

12. Sayyad M, Conine TA. Effect of exercise, bracing and electrical surface stimulation on idiopathic scoliosis: a preliminary study. Int J Rehabil Res. 1994:17(1):70-4.

13. van den Bogaart M, van Royen BJ, Haanstra TM, et al. Predictive factors for brace treatment outcome in adolescent idiopathic scoliosis: a bestevidence synthesis. Eur Spine J. 2019;28(3):511-25.

14. Negrini S, Donzelli S, Negrini A, et al. Specific exercises reduce the need for bracing in adolescents with idiopathic scoliosis: a practical clinical trial. Ann Phys Rehabil Med. 2019;62(2):69-76.

15. Zapata KA, Sucato DJ, Jo CH. Physical therapy scoliosis-specific exercises may reduce curve progression in mild adolescent idiopathic scoliosis curves. Pediatr Phys Ther. 2019;31(3):280-5.

16. Park JH, Jeon HS, Park HW. Effects of the Schroth exercise on idiopathic scoliosis: a meta-analysis. Eur J Phys Rehabil Med. 2018;54(3):440-9.

17. Thompson JY, Williamson EM, Williams MA, Heine PJ, Lamb SE, ACTIVATeS Study Group. Effectiveness of scoliosis-specific exercises for adolescent idiopathic scoliosis compared with other non-surgical interventions: a systematic review and meta-analysis. Physiotherapy. 2019;105(2):214-34.

18. Schreiber S, Parent EC, Hill DL, et al. Schroth physiotherapeutic scoliosisspecific exercises for adolescent idiopathic scoliosis: how many patients require treatment to prevent one deterioration? - results from a randomized controlled trial—"SOSORT 2017 Award Winner." Scoliosis Spinal Disord. 2017;14(12):26.

19. Berdishevsky H, Lebel VA, Bettany-Saltikov J, et al. Physiotherapy scoliosisspecific exercises-a comprehensive review of seven major schools. Scoliosis Spinal Disord. 2016;11:20.

20. Mao S, Shi B, Xu L, et al. Initial Cobb angle reduction velocity following bracing as a new predictor for curve progression in adolescent idiopathic scoliosis. Eur Spine J. 2016;25(2):500-5.

\section{Publisher's Note}

Springer Nature remains neutral with regard to jurisdictional claims in published maps and institutional affiliations.

Ready to submit your research? Choose BMC and benefit from

- fast, convenient online submission

- thorough peer review by experienced researchers in your field

- rapid publication on acceptance

- support for research data, including large and complex data types

- gold Open Access which fosters wider collaboration and increased citations

- maximum visibility for your research: over 100M website views per year

At BMC, research is always in progress.

Learn more biomedcentral.com/submissions 